\title{
Efeito da luz ultravioleta na eclodibilidade e viabilidade de pintos provenientes de ovos férteis sujos*
}

\section{Effect of ultraviolet light in hatchability and viability of chicks from dirty fertile eggs}

\author{
Fernanda Mara Aragão Macedo Pereira, ${ }^{* *}$ Lucas Philipe Vasconcelos Gomes de Sousa, ${ }^{* *}$ Jéssica Delazzeri Rama, ${ }^{* *}$ \\ Bruno Stéfano Lima Dallago, ${ }^{* *}$ Simone Perecmanis, ${ }^{* * *}$ Francisco Ernesto Moreno Bernal ${ }^{* *}$
}

\begin{abstract}
Resumo
Considerando a necessidade de se desenvolver estratégias para a incubação de ovos sujos e a demanda de se utilizar métodos renováveis de sanitização, a utilização da luz ultravioleta para desinfecção de ovos incubáveis sujos foi o objetivo desta pesquisa. Foram avaliados ovos sem desinfecção (C-), desinfetados com paraformaldeído (C+), e expostos a tempos diferentes de exposição ultravioleta: UV 3'30", UV 4'30" e UV 5'30". Os ovos C(+) e os expostos à UV por 3'30" e 5'30" tiveram uma redução significativa na quantidade de colônias na casca dos ovos em relação ao C(-), variando de 0.64 a 1 logUFC/g. Os tratamentos C(+), UV 3'30" e UV 5'30" foram aplicados para avaliação da incubabilidade dos ovos. A eclodibilidade do tratamento UV 3'30" (70,51\%) foi superior ao UV 5'30" (51,16\%) e similar ao C(+) (55,81\%). Conclui-se que o tratamento UV 3'30" é eficaz na redução da contaminação microbiológica de ovos sujos e não afeta negativamente a eclodibilidade e a viabilidade dos pintinhos nascidos.
\end{abstract}

Palavras-chave: desinfecção, pintos, ovos, UV.

\begin{abstract}
Considering the need to develop strategies for dirty eggs incubation and the demand to use renewable methods of sanitation, the use of ultraviolet light for disinfecting hatching dirty eggs was the objective of this research. Eggs not disinfected (C-), disinfected with paraformaldehyde (C+) and exposed to different times of UV radiation (UV 3'30", UV 4'30" and UV 5'30") were tested. The eggs $\mathrm{C}(+)$ and those exposed to UV for 3'30" and 5'30" presented a significant reduction on the number of colonies of eggshells comparing to $\mathrm{C}(-)$, with a 0.64 to $1 \mathrm{log} U F C / g$ variation. The treatments $\mathrm{C}(+)$, UV 3'30" and UV 5'30" were applied in an incubation phase. The hatchability of treatment UV 3'30" (70,51\%) was superior to UV 5'30" $(51,16 \%)$ and alike C(+) $(55,81 \%)$. In conclusion, the treatment UV 3 '30" is effective in reducing microbiologic contamination of dirty eggs and do not affect negatively hatchability and quality of chicks.
\end{abstract}

Keywords: chicks, disinfection, eggs, UV.

\section{Introdução}

A incubação de ovos visivelmente sujos, de aves com sintomatologia clínica ou subclínica de doenças que afetam o intestino, postos em ninhos com cama suja ou no piso, não é indicada por razões de biosseguridade, pois pode elevar o risco de contaminação dos pintinhos dentro de uma mesma unidade de incubação por vários microrganismos patogênicos, como os dos gêneros Escherichia, Aspergillus, Pseudomonas, Campylobacter, Salmonella, dentre outros (Rossi et al., 2012; Buhr et al., 2013). A cutícula que envolve o ovo evita que patógenos invadam seu interior através dos poros na casca, e a limpeza dos ovos pode causar a perda de sua integridade. Esse é um dos motivos pelos quais se evita o uso de ovos visivelmente sujos na incubação (Peebles et al., 1998; De Reu et al., 2006b;
Gole et al., 2014; Scanes, 2015), pois estes necessitariam ser limpos previamente à desinfecção.

Contudo, produtores de menor porte, de criação caipira ou de criação de aves silvestres e exóticas frequentemente incubam ovos postos em ninhos com cama suja ou piso, necessitando de um método de desinfecção seguro disponível visto que a carga bacteriana pode ser elevada devido ao seu maior contato com o ambiente (Parisi et al., 2015; Pesavento et al., 2017).

Os métodos comumente utilizados na desinfecção de ovos são fumigação, pulverização e imersão por compostos químicos, principalmente formaldeído e amônia quaternária (Rui, 2011; Turtoi e Borda, 2014), que podem ser nocivos à saúde e ao meio ambiente (Cony e Zocche, 2004; Ünsaldı e Çiftçl, 2010; Durmus, 2012). A utilização da luz ultravioleta (UV-C) é uma alternativa

${ }^{*}$ Recebido em 13 de julho de 2018 e aceito em 27 de dezembro de 2018.

**Laboratório de Bem-Estar Animal, Faculdade de Agronomia e Medicina Veterinária, Universidade de Brasília, Brasília, Brasil.

***Laboratório de Microbiologia Médica Veterinária, Faculdade de Agronomia e Medicina Veterinária, Universidade de Brasília, Brasília, Brasil. 
que já se mostrou viável para a desinfecção de diferentes materiais e superfícies (Oluwafemi e Ayobami, 2004; Hijnen et al., 2006; Koutchma et al., 2009; Lah et al., 2012; Yousra et al., 2013; Turtoi e Borda, 2014).

O objetivo da presente pesquisa foi avaliar o potencial da luz UV-C, em um sistema de menor escala, na redução da contagem de bactérias presentes na superfície de ovos férteis sujos e avaliar seu efeito sofre as taxas de nascimentos, mortalidade e morbidade dos pintinhos quando comparada à desinfecção por fumigação com paraformaldeído e à ausência de método desinfetante.

\section{Material e métodos}

O experimento foi autorizado pela Comissão de Ética no Uso de Animais da Universidade de Brasília (UnB Doc. 28840/2015) e foi realizado nos laboratórios de Bem-Estar Animal e de Microbiologia Médica Veterinária da Faculdade de Agronomia e Medicina Veterinária e no Alojamento de Animais do Biotério da Faculdade de Saúde da Universidade de Brasília.

A pesquisa foi realizada em duas fases. Primeiro, fez-se uma avaliação microbiológica dos ovos após os tratamentos e, posteriormente, foram selecionados três tratamentos em que os ovos seguiram para incubação e avaliação dos nascimentos. O delineamento experimental da primeira fase foi inteiramente casualizado e, da segunda, em blocos casualizados.

Primeiramente, foram utilizados 275 ovos férteis, sujos e manchados (fezes, sangue e cama), provenientes de avós da linhagem Hubbard, de idades mistas variando entre 30 e 50 semanas. Esses ovos foram colhidos de ninhos manuais de alumínio. Um total de 35 ovos foram utilizados em cada um de cinco tratamentos, sendo eles ovos não desinfetados (C-), expostos à ultravioleta por três minutos e meio (UV 3'30"), expostos por quatro minutos e meio (UV 4'30"), expostos por cinco minutos e meio (UV 5'30") e ovos desinfetados com paraformaldeído(C+).

Foram utilizadas esponjas de aço estéreis individuais para a retirada do excesso de sujeira da superfície dos ovos, e o excesso de poeira presente na casca foi removido com panos secos individuais estéreis. Após limpeza parcial e pesagem, os ovos prosseguiram com os tratamentos planejados. A exposição à luz ultravioleta foi realizada em capela de fluxo laminar (Streamline ${ }^{\circledR}$ Class II, Biological Safety Cabinet, ESCO; dimensões internas $122 \times 58 \times 67 \mathrm{~cm}$ ) sendo uma fonte única de emissão de luz. Os ovos receberam $232 \mathrm{uW} / \mathrm{cm}^{2}$ de radiação (FieldMax ${ }^{\circledR}$ II-TOP, Coherent), posicionados a aproximadamente $55 \mathrm{~cm}$ da lâmpada ultravioleta. Os ovos cujo tratamento consistia na radiação UV-C foram enfileirados numa bandeja rotatória centralizada no interior do equipamento, que proporcionava uma rotação completa por minuto. Os ovos do grupo $\mathrm{C}(+)$ foram desinfetados com fumigação de paraformaldeído, em umidade superior a $70 \%$.

Para definir o potencial de desinfecção de cada tratamento foi realizada coleta das amostras utilizando-se da técnica de lavagem superficial e cultura bacteriana em placas de contagem (De Reu et al., 2006a; Silva et al., 2010; Wells et al., 2010). A lavagem superficial foi realizada em sacos plásticos individuais estéreis, massageando-se a superfície dos ovos por 30 segundos em $20 \mathrm{ml}$ de Água Peptonada Tamponada (BPW da sigla em inglês), seguida de uma diluição de 1:100 da amostra para realizar a incubação em ágar padrão de contagem (PCA), a $37^{\circ} \mathrm{C}$ por 48 horas.

Após o período de incubação, a contagem das colônias foi realizada com o auxílio de um fundo escuro e uma caneta para marcação de coloração preta. Foi calculado o número de unidades formadoras de colônia dos ovos (UFC/g e logUFC/g), baseado nos pesos dos mesmos e número de colônias contadas por placa.

Após finalização do primeiro experimento, foram incubados 315 ovos sujos e não lavados para avaliação do impacto da desinfecção na eclodibilidade e viabilidade dos pintos. Cada grupo foi composto por um total de 105 ovos férteis, correspondentes aos tratamentos selecionados a partir da Fase 1. Os tratamentos consistiram de controle positivo $(\mathrm{C}+)$, correspondente ao uso de paraformaldeído como desinfetante, tratamento com luz ultravioleta durante três minutos e meio (UV 3'30") e tratamento com luz ultravioleta durante cinco minutos e meio (UV 5'30"). As incubadoras foram ajustadas para se manter em torno de $37.5^{\circ} \mathrm{C}$ de temperatura, $65 \%$ de umidade e rotar os ovos a cada hora.

Para esse procedimento, os ovos foram limpos com o auxílio de esponjas de aço e panos secos individuais, estéreis. Em seguida, procedeu-se com a aplicação dos tratamentos. Após a desinfecção, os ovos de cada tratamento foram dispostos em diferentes incubadoras (Premium Ecologica IP 70), após ovoscopia, marcação e pesagem. Ovoscopias semanais foram realizadas a fim de avaliar o crescimento embrionário nos ovos durante o período de incubação.

Aos dezoito dias de incubação foram retirados os roletes das incubadoras e dispostas telas metálicas antiderrapantes para acomodar os ovos visando o nascimento dos pintinhos. A temperatura das máquinas incubadoras foi reduzida para $34^{\circ} \mathrm{C}$ e a umidade foi mantida em torno de $70 \%$ até o final do tempo prudente, previsto para eclosão.

Os pintos nascidos de cada tratamento foram contabilizados, assim como as mortalidades embrionárias ocorridas em diferentes estágios de desenvolvimento, avaliadas após ovoscopia e diagnóstico macroscópico. A inspeção visual de todos os ovos não eclodidos foi realizada, separando-se os ovos inférteis dos ovos que apresentaram mortalidade embrionária inicial ( 1 - 7 dias), média ( 8 - 14 dias) e tardia (15 - 21 dias), assim como foram contabilizados os embriões completamente desenvolvidos que bicaram a casca do ovo para eclosão porém morreram.

Para os pintinhos nascidos vivos, procedeu-se a pesagem, sexagem e avaliação física para classificá-los de acordo com padrões morfológicos e comportamentais. A classificação dos pintinhos foi realizada de forma categórica binominal para os parâmetros atividade, aparência das penas, abertura e brilho dos olhos, conformação das pernas e cicatrização do umbigo, sendo que os pintinhos com características desejáveis receberam pontuação 1 e os apresentando alterações, como sinais de apatia, infecção e deformações, receberam 0 .

Os dados foram analisados no programa Statistical Analysis Software (SAS). Os resultados da primeira fase foram trabalhados utilizando-se do procedimento GLM (General Linear Model) para testar os efeitos do tratamento, de efeito fixo, sobre 
os valores de unidades formadoras de colônia encontrados, sendo os resultados comparados com o teste Tukey-Kramer (diferenças de $\mathrm{P}<0.05$ foram considerados estatisticamente significantes). Para testar os efeitos da repetição, tratamento, sexo e a interação entre eles bem como o peso do ovo como covariável na eclodibilidade e saúde dos pintinhos, foi utilizado o procedimento Glimmix e os resultados comparados com o teste Tukey-Kramer. O teste de Qui-quadrado foi usado para testar se houve diferença entre os tratamentos sobre a mortalidade por período de desenvolvimento, inicial (primeira semana), média (segunda semana) e tardia (terceira semana), e se os pintinhos mortos bicaram a casca ou não.

\section{Resultados e discussão}

Os valores contabilizados das unidades formadoras de colônia para todos os tratamentos estudados encontram-se na Tabela 1.

Tabela 1: Valores de média e desvio padrão do total de colônias que apresentaram crescimento, nos diferentes tratamentos, calculadas em logUFC/g e logUFC/ovo

\begin{tabular}{lcc}
\hline Tratamento & $\log _{10}$ UFC/g & $\log _{10}$ UFC/ovo \\
\hline C(-) & $3.00 \pm 0.72^{\mathrm{a}}$ & $4.80 \pm 0.72^{\mathrm{a}}$ \\
UV 3'30" & $1.95 \pm 1.10^{\mathrm{b}}$ & $3.43 \pm 1.74^{\mathrm{b}}$ \\
UV 4'30" & $2.43 \pm 1.27^{\mathrm{ab}}$ & $4.07 \pm 1.79^{\mathrm{ab}}$ \\
UV 5'30" & $1.99 \pm 1.04^{\mathrm{b}}$ & $3.47 \pm 1.69^{\mathrm{b}}$ \\
C(+) & $2.36 \pm 0.87^{\mathrm{b}}$ & $3.92 \pm 1.50^{\mathrm{b}}$
\end{tabular}

abLetras sobrescritas na mesma coluna indicam diferença estatística entre tratamentos $(\mathrm{P}<0.05)$ pelo teste de Tukey-Kramer.

A concentração bacteriana nos ovos não tratados (C-) foi mais elevada, diferindo dos demais tratamentos. Nos ovos expostos à luz UV por 4'30" a contagem foi elevada, porém não diferiu estatisticamente dos ovos expostos aos outros tratamentos, inclusive aos ovos não tratados (Tabela 1). Parte dos estudos encontrados na literatura concluem que o aumento do tempo de exposição (Kuo et al., 1997; Chavez et al., 2002; Wells et al., 2010; Turtoi e Borda, 2014)eggs were exposed to UV treatment (7.35 mW/cm2 e da intensidade (Gao et al., 1997; Kuo et al., 1997) produzem reduções expressivas na contaminação dos ovos. O fato do tratamento UV 4'30" não ter reduzido significativamente a carga bacteriana na superfície dos ovos pode estar relacionado à carga microbiana inicial ou à presença de espécies bacterianas menos susceptíveis ao processo de desinfecção com UV (Kuo et al., 1997; Coufal et al., 2003; De Reu et al., 2006a). São necessárias novas repetições desse procedimento para avaliar o nível de contaminação superficial desses ovos que possam ser comparadas para uma melhor avaliação do que foi encontrado nesse estudo, promovendo resultados mais conclusivos.

Foi verificada uma redução no número de colônias de até 1 logUFC/g, ou 1.37 e 1.32 logUFC/ovo, entre os tratamentos UV 3'30" e 5'30", respectivamente, em relação ao C(-) (Tabela 1). A redução na carga bacteriana encontrada para os ovos tratados com ultravioleta corresponde a aproximadamente $29 \%$ em relação aos ovos não desinfetados. Essa redução na carga bacteriana superficial dos ovos foi, inclusive, ligeiramente maior do que a verificada com o $\mathrm{C}(+)$.
Wells et al. (2010) verificaram também uma redução significativa na contagem de bactérias superficiais nos ovos entre o grupo controle e os diferentes tratamentos estipulados. A redução encontrada para a exposição por 4 minutos foi de 1.5 logUFC/ ovo (39\%) e, para 8 minutos, 2 logUFC/ovo (68\%).

Coufal et al. (2003) também estudaram os efeitos da UV-C em ovos incubáveis e verificaram uma redução de 1.8 a 1.9 logUFC/ovo para ovos expostos à UV por 4 minutos. Embora as reduções nos resultados encontrados sejam maiores aos do presente estudo, a diferença pode estar relacionada à metodologia empregada para coleta das amostras. Esses mesmos pesquisadores utilizaram 21 ovos, divididos em três procedimentos distintos, e realizaram a massagem com Água Peptonada Tamponada nos sacos estéreis por 5 segundos, 0 que pode explicar a pequena diferença entre os dois resultados, uma vez que o presente trabalho utilizou uma quantidade maior de ovos e massageou-os na solução por um tempo mais prolongado, o que propiciaria a coleta de uma maior quantidade de bactérias.

Em um estudo realizado por Chavez et al. (2002) investigando os efeitos da UV-C na superfície de ovos incubáveis foi constatada uma redução significativa de $32 \%$ a $60 \%$ (entre 1 e 3 logUFC/ ovo) na contagem de colônias para exposições de 30 e 60 segundos, respectivamente. Esse resultado é semelhante ao encontrado no presente estudo, que observou uma redução de 1.32 a 1.37 logUFC/ovo para os tempos de exposição UV 3'30" e UV 5'30". O resultado encontrado pelos autores supracitados, indicativo de uma redução de até 3 logUFC/ovo para um tempo de exposição de 1 minuto, que é relativamente curto, difere significativamente se comparado aos 1.37 logUFC/ovo da presente pesquisa. Essa diferença pode ser explicada com base nas divergências entre a metodologia empregada nos trabalhos, no qual Chavez et al. (2002) dispuseram lâmpadas UV em várias posições em relação aos ovos, o período de massagem com BPW nos sacos estéreis foi de 5 segundos, e o total de ovos analisados foi 3 por tratamento e repetição (totalizando 9 ovos). Embora não se possa afirmar uma causa para essa discrepância entre resultados, a redução de, aproximadamente, 1 logUFC/g, (próximo a $30 \%$ ) observada no presente trabalho foi considerada satisfatória em termos de desinfeção se comparada ao controle positivo e com a literatura (Chavez et al., 2002; Wells et al., 2010) eggs were exposed to UV treatment $(7.35 \mathrm{~mW} / \mathrm{cm} 2$.

Poucos estudos avaliaram, porém, a influência da desinfecção em ovos visivelmente sujos, fator que pode alterar significativamente a contagem de bactérias superficiais e internas nos ovos. De Reu et al. (2006a) testou a desinfeção por UV-C em ovos comerciais limpos e sujos utilizando câmaras com lâmpadas ultravioleta em uma esteira de transporte dos ovos, onde os ovos percorriam o trajeto em 4.7 segundos, obtendo resultado satisfatório para os ovos limpos em comparação com o controle, com uma redução de 0.9 logUFC/ovo (20\%). Os autores referidos não verificaram, porém, redução significativa na carga bacteriana de ovos sujos expostos ao UV, com a redução de somente 0.18 logUFC/ ovo (3\%). Esse valor é consideravelmente menor do que os 1.37 logUFC/ovo encontrados nessa pesquisa, o que leva a crer na possibilidade do curto tempo de incidência de luz UV empregado naquela pesquisa ter influenciado negativamente no resultado. Ainda, aparentemente, não foi retirado o excesso de sujeira, como fezes e cama, da casca dos ovos previamente ao procedimento de coleta de amostra, o que pode ter sido 
um fator importante na dificuldade de desinfecção com UV das bactérias menos superficiais, pois as partículas de sujeira impedem a penetração da radiação nas camadas mais profundas (Guerrero-Beltrán e Barbosa-Cánovas, 2004; De Reu et al., 2006a; Pedrós-Garrido et al., 2018).

Os pesos de todos os ovos utilizados nessa fase do experimento foram uniformes e não foi constatada influência do peso sobre a eclodibilidade dos pintinhos (Tabela 2).

Tabela 2: Nível de contaminação e eclodibilidade de ovos sujos incubados expostos à luz ultravioleta (UV) em diferentes tempos

\begin{tabular}{lccc}
\hline Parâmetros & UV 3'30" (\%) & UV 5'30" (\%) & C (+) (\%) \\
\hline Contaminação & $1,90^{\mathrm{b}}$ & $1,90^{\mathrm{b}}$ & $9.52^{\mathrm{a}}$ \\
Eclodibilidade & $70,51^{\mathrm{a}}$ & $51,16^{\mathrm{b}}$ & $55,81^{\mathrm{ab}}$ \\
\hline
\end{tabular}

abLetras sobrescritas na mesma linha indicam diferença estatística entre tratamentos $(P<0.05)$ pelo teste de Tukey-Kramer.

Foi verificado que houve efeito do tratamento realizado sobre a eclodibilidade dos ovos (Tabela 2). Ovos expostos ao tratamento UV 3'30" apresentaram uma eclodibilidade média de $70,51 \%$, que foi superior à apresentada pelo tratamento UV 5'30", de $51,16 \%$. O tratamento C(+), cuja eclodibilidade foi de $55,81 \%$, não demonstrou diferença estatística com os demais tratamentos. Observa-se o destaque do tratamento UV 3'30" sobre os demais tratamentos, principalmente por não apresentar diferença estatística sobre o tratamento com paraformaldeído $(\mathrm{C}+)$, tradicional na indústria avícola, e ter uma eclodibilidade maior que o tratamento UV 5'30", sugerindo uma maior segurança com aquele tempo de exposição.

A menor eclodibilidade absoluta dos ovos do grupo controle (+) quando comparados aos ovos UV 3'30" também pode ser devida aos efeitos do desinfetante sobre os embriões, uma vez que alguns produtos químicos podem ser demasiado tóxicos, além de afetar a cutícula e as propriedades da casca do ovo, prejudicando o desenvolvimento embrionário (Zeweil et al., 2015). Os efeitos tóxicos do paraformaldeído já são reconhecidos há anos (Leeson e Summers, 2000; Turtoi e Borda, 2014; Zeweil et al., 2015) constataram que aves provenientes de desinfecção com esse composto tiveram menor peso, retardo no desenvolvimento e baixas taxas mitóticas em sistema nervoso central e cutâneo durante a incubação em comparação ao uso de soluções desinfetantes naturais.

Quando analisamos os ovos que apodreceram durante o procedimento, com crescimento microbiológico visível no interior dos mesmos e que apresentaram odor fétido, o maior número foi observado no tratamento onde os ovos foram desinfetados com paraformaldeído (Tabela 2). Pode-se inferir que a desinfecção com este composto não foi eficiente o bastante no controle da carga bacteriana ou infecção interna dos ovos nesta pesquisa. Visto que esse processo de desinfecção envolve alta umidade e realizou-se a retirada do excesso de sujidade dos ovos com esponjas, lesando a cutícula, o influxo de micro-organismos para o interior do ovo é uma possibilidade, o que acarretaria em um maior nível de contaminação interna e afetaria substancialmente os parâmetros de eclosão desse grupo.
Nesse estudo, foram encontradas alterações ao exame físico dos pintinhos, compatíveis com o que ocorre no ambiente produtivo, em todos os tratamentos. Dentre elas onfalite, inchaço articular, deformação das pernas e retenção do saco vitelínico. Alguns animais apresentaram alterações posturais como incapacidade de se manter em estação, dificuldade de deambulação e lateralização corporal sem que fossem identificados visíveis problemas osteoarticulares. De todas as características avaliadas, apenas o nível de atividade demonstrou sofrer influência do tratamento realizado. Os animais nascidos dos tratamentos UV 3'30" e controle (+) apresentaram-se mais ativos que os animais nascidos do tratamento UV 5'30". Alguns animais encontravam-se visivelmente apáticos, com olhos parcialmente fechados, se movimentando pouco pela incubadora e não vocalizando. Aliado a isso, aproximadamente $20 \%$ dos pintinhos que vieram a óbito do tratamento UV 5'30" tiveram dificuldade em sair do ovo, como averiguado através de exame macroscópico (Tabela 3). Ambos os dados corroboram com a suspeita de que um maior tempo de exposição à luz ultravioleta possa afetar negativamente a saúde dos animais em desenvolvimento, conforme verificado por demais autores (Veterány et al., 2004; Wells et al., 2010; Khodnapur et al., 2015).

Tabela 3: Avaliação da mortalidade embrionária pelo embriodiagnóstico de ovos sujos expostos à luz ultravioleta (UV) em diferentes tempos

\begin{tabular}{|l|c|c|c|}
\hline \multicolumn{1}{|c|}{ Parâmetros } & UV 3'30" (\%) & UV 5'30" (\%) & C(+) (\%) \\
\hline Mortalidade inicial & 10,4 & 11,9 & 17,9 \\
\hline Mortalidade média & 7,8 & 3,6 & 5,3 \\
\hline Mortalidade tardia & $10,4^{\mathrm{a}}$ & $31,0^{\mathrm{b}}$ & $20,4^{\mathrm{a}, \mathrm{b}}$ \\
\hline Casca bicada & 13,04 & 21,43 & 10,53 \\
\hline
\end{tabular}

a,bLetras sobrescritas na mesma linha indicam diferença entre tratamentos pelo teste $z$ de Qui-quadrado $(P<0,05)$.

Houve relação entre o tratamento e a mortalidade na terceira semana de desenvolvimento, sendo maior no UV5'30" do que nos demais tratamentos. O óbito pode ocorrer durante todo o período de incubação e estar relacionada a erros no processo, como oscilações drásticas de temperatura e umidade, anormalidades cromossômicas letais, qualidade da casca, duração do armazenamento, mal posicionamento embrionário e contaminação. Esses problemas afetam principalmente os embriões em fase inicial e tardia (Fairchild, 2003; Lauvers e Ferreira, 2011).

Devido à natureza da limpeza com esponjas de aço realizada nos ovos sujos do presente experimento, a camada cuticular pode ter sido afetada de maneira a controlar menos eficientemente as trocas gasosas e líquidas entre o interior do ovo e o ambiente. Tal controle proporcionado pela casca é responsável pela manutenção de uma temperatura ótima para o embrião, pela perda controlada de peso do ovo e pelas trocas gasosas de oxigênio e gás carbônico entre seu interior e exterior (Simons e Wiertz, 1966; Molenaar et al., 2010; King'ori, 2012; Zeweil et al., 2015).

Wells et al. (2010) verificaram em seu experimento que um maior tempo de exposição ultravioleta causou superaquecimento do interior dos ovos, atingindo até $37^{\circ} \mathrm{C}$. Uma hipertermia 
pode causar redução da eclodibilidade, redução do peso do pintinho, problemas locomotores, aumento da mortalidade embrionária em fase inicial e final e redução da capacidade de transferência de proteínas do ovo para o embrião (Molenaar et al., 2010; Ipek et al., 2014; van der Pol et al., 2014). Essa maior fragilidade pode ter afetado negativamente os ovos expostos à ultravioleta por períodos prolongados uma vez que um possível superaquecimento inicial pode causar maior mortalidade e desenvolvimento anormal embrionário, além de poder causar maiores índices de condensação (Molenaar et al., 2010; Wells et al., 2010; Nangsuay et al., 2016).

\section{Referências}

BUHR, R. J.; SPICKLER, J. L.; RITTER, A. R.; BOURASSA, D. V.; COX, N. A.; RICHARDSON, L. J.; WILSON, J. L. Efficacy of combination chemicals as sanitizers of Salmonella-inoculated broiler hatching eggshells. The Journal of Applied Poultry Research, v. 22, n. 1, p. 27-35, 2013.

CHAVEZ, C.; KNAPE, K. D.; COUFAL, C. D.; CAREY, J. $B$. Reduction of eggshell aerobic plate counts by ultraviolet irradiation. Poultry Science, v. 81, n. 8, p. 1132-1135, 2002.

CONY, A. V.; ZOCCHE, A. T. Manejo de frango de corte. In: Mendes, A.A.; Naas, I.A.; Macari, M. Produção de frangos de corte. Campinas: Facta, 2004.

COUFAL, C. D.; CHAVEZ, C.; KNAPE, K. D.; CAREY, J. B. Evaluation of a method of ultraviolet light sanitation of broiler hatching eggs. Poultry Science, v. 82, n. 5, p. 754-759, 2003.

DE REU, K.; GRIJSPEERDT, K.; HERMAN, L.; HEYNDRICKX, M.; UYTTENDAELE, M.; DEBEVERE, J.; PUTIRULAN, F. F.; BOLDER, N. M. The effect of a commercial UV disinfection system on the bacterial load of shell eggs. Letters in Applied Microbiology, v. 42, n. 2, p. 144-148, 2006a.

DE REU, K.; GRIJSPEERDT, K.; MESSENS, W.; HEYNDRICKX, M.; UYTTENDAELE, M.; DEBEVERE, J.; HERMAN, L.

Eggshell factors influencing eggshell penetration and whole egg contamination by different bacteria, including Salmonella enteritidis. International Journal of Food Microbiology, v. 112, n. 3, p. 253-260, 2006b.

DURMUS, I. Determining effects of use of various disinfecting materials on hatching results and total bacterial count. Asian Journal of Animal Veterinary Advances, v. 7, n. 8, p. 739-744, 2012.

FAIRCHILD, B. Minimización de la mortalidad embrionaria. Industria Avícola, v. 50, n. 9, p. n53, 2003.

GAO, F.; E. STEWART, L.; JOSEPH, S.; E. CARR, L. Effectiveness of ultraviolet irradiation in reducing the numbers of Salmonella on eggs and egg belt conveyor materials. Applied Engineering in Agriculture, v. 13, n. 3, p. 355-359, 1997.

GOLE, V. C.; CHOUSALKAR, K. K.; ROBERTS, J. R.; SEXTON, M.; MAY, D.; TAN, J.; KIERMEIER, A. Effect of egg washing and correlation between eggshell characteristics and egg penetration by various Salmonella typhimurium strains. PloS One, v. 9, n. 3, p. e90987, 2014.

GUERRERO-BELTRÁN, J. A.; BARBOSA-CÁNOVAS, G. V. Advantages and limitations on processing foods by UV light. Food Science and Technology International, v. 10, n. 3, p. 137-147, 2004.

\section{Considerações finais}

Os resultados encontrados ao tratar os ovos com UV-C, em especial quando a duração da exposição durante três minutos e meio na desinfecção de ovos férteis, foi considerada satisfatória. Entretanto, pode ser observada também a necessidade de que sejam realizados novos testes para verificar quais os possíveis efeitos deletérios que a exposição à luz UV e a limpeza física da superfície do ovo exercem sobre o embrião em desenvolvimento e o ambiente interno do ovo para que a técnica possa ser utilizada com maior segurança.

HIJNEN, W. A. M.; BEERENDONK, E. F.; MEDEMA, G. J. Inactivation credit of UV radiation for viruses, bacteria and protozoan (oo)cysts in water: a review. Water Research, v. 40, n. 1, p. 3-22, 2006.

IPEK, A.; SAHAN, U.; BAYCAN, S. C.; SOZCU, A. The effects of different eggshell temperatures on embryonic development, hatchability, chick quality, and first-week broiler performance. Poultry Science, v. 93, n. 2, p. 464-472, 2014.

KHODNAPUR, B. S.; INAMDAR, L. S.; NINDI, R. S.; MATH, S. A.; MULIMANI, B. G.; INAMDAR, S. R. UV laser radiation alters the embryonic protein profile of adrenal-kidney-gonadal complex and gonadal differentiation in the lizard, Calotes versicolor. International Journal of Radiation Biology, v. 91, n. 2, p. 194-201, 2015.

KING'ORI, A. M. Egg Quality deffects: Types, causes and occurrence: a review. Journal of Animal Production Advances, v. 2, n. 8, p. 350-357, 2012.

KOUTCHMA, T. N.; FORNEY, L. J.; MORARU, C. I. Ultraviolet light in food technology: principles and applications. New York: Taylor and Francis Group, 2009.

KUO, F.; RICKE, S.; CAREY, J. Shell Egg Sanitation: UV radiation and egg rotation to effectively reduce populations of aerobes, yeasts, and molds. Journal of Food Protection, v. 60, n. 6, p. 694-697, 1997.

LAH, E. F. C.; MUSA, R. N. A. R.; MING, H. T. Effect of germicidal UV-C light (254 $\mathrm{nm}$ ) on eggs and adult of house dustmites, Dermatophagoides pteronyssinus and Dermatophagoides farinae (Astigmata: Pyroglyhidae). Asian Pacific Journal of Tropical Biomedicine, v. 2, n. 9, p. 679-683, 2012.

LASAGABASTER, A.; ARBOLEYA, J. C.; MARAÑÓN, I. M. DE. Pulsed light technology for surface decontamination of eggs: Impact on Salmonella inactivation and egg quality. Innovative Food Science \& Emerging Technologies, v. 12, n. 2, p. 124-128, 2011.

LAUVERS, G.; FERREIRA, V. P. Fatores que afetam a qualidade dos pintos de um dia, desde a incubação até o recebimento na granja. Revista Científica Eletrônica de Medicina Veterinária, v. 9, n. 16, p. 1-19, 2011.

LEESON, S.; SUMMERS, J. Broiler breeder production. London: Nottingham University Press, 2000.

MOLENAAR, R.; MEIJERHOF, R.; ANKER, I. VAN DEN; HEETKAMP, M. J. W.; BORNE, J. J. G. C. VAN DEN; KEMP, B.; BRAND, H. VAN DEN. Effect of eggshell temperature and oxygen concentration on survival rate and nutrient utilization in chicken embryos. Poultry Science, v. 89, n. 9, p. 2010-2021, 2010. 
NANGSUAY, A.; MEIJERHOF, R.; ANKER, I. VAN DEN; HEETKAMP, M. J. W.; MORITA, V. D. S.; KEMP, B.; BRAND, H. VAN DEN. Effects of breeder age, broiler strain, and eggshell temperature on development and physiological status of embryos and hatchlings. Poultry Science, v. 95, n. 7, p. 1666-1679, 2016.

OLUWAFEMI, A. I.; AYOBAMI, A. J. Effect of ultraviolet radiation on the hatchability and survival of eggs and larvae of sheep nematode. Journal of Veterinary Science, v. 5, n. 1, p. 59-62, 2004.

PARISI, M. A.; NORTHCUTT, J. K.; SMITH, D. P.; STEINBERG, E. L.; DAWSON, P. L. Microbiological contamination of shell eggs produced in conventional and free-range housing systems. Food Control, v. 47, p. 161-165, 2015.

PEDRÓS-GARRIDO, S.; CONDÓN-ABANTO, S.; CLEMENTE, I.; BELTRÁN, J. A.; LYNG, J. G.; BOLTON, D.; BRUNTON, N.; WHYTE, P. Efficacy of ultraviolet light (UV-C) and pulsed light (PL) for the microbiological decontamination of raw salmon (Salmo salar) and food contact surface materials. Innovative Food Science \& Emerging Technologies, v. 50, p. 124-131, 2018.

PEEBLES, E. D.; PANSKY, T.; DOYLE, S. M.; BOYLE, C. R.; SMITH, T. W.; LATOUR, M. A.; GERARD, P. D. Effects of dietary fat and eggshell cuticle removal on egg water loss and embryo growth in broiler hatching eggs. Poultry Science, v. 77, n. 10, p. 1522-1530, 1998.

PESAVENTO, G.; CALONICO, C.; RUNFOLA, M.; LO NOSTRO, A. Free-range and organic farming: Eggshell contamination by mesophilic bacteria and unusual pathogens. The Journal of Applied Poultry Research, v. 26, n. 4, p. 509-517, 2017.

POL, C. W. VAN DER; ROOVERT-REIJRINK, I. A. M. VAN; MAATJENS, C. M.; ANKER, I. VAN DEN; KEMP, B.; BRAND, H. VAN DEN. Effect of eggshell temperature throughout incubation on broiler hatchling leg bone development. Poultry Science, v. 93, n. 11, p. 2878-2883, 2014.

ROSSI, D. A.; FONSECA, B. B.; MELO, R. T. DE; FELIPE, G. DA S.; SILVA, P. L. DA; MENDONÇA, E. P.; FILGUEIRAS, A. L. L.; BELETTI, M. E. Transmission of Campylobacter coli in chicken embryos. Brazilian Journal of Microbiology, v. 43, n. 2, p. 535543, 2012.
RUI, B. R. Principais métodos de desinfecção e desinfetantes utilizados na avicultura. Revista Científica Eletrônica de Medicina Veterinária, v. 9, n. 16, 2011.

SCANES, C. Sturkie's Avian Physiology. New York: Elsevier, 2015.

SILVA, N.; JUNQUEIRA, V.; SILVEIRA, N.; TANIWAKI, M.; SANTOS, R.; GOMES, R. Manual de métodos de análise microbiológica de alimentos e água. São Paulo: Varela, 2010.

SIMONS, P. C. M.; WIERTZ, G. The ultra-structure of the surface of the cuticle of the hen's egg in relation to egg cleaning. Poultry Science, v. 45, n. 6, p. 1153-1162, 1966.

TURTOI, M.; BORDA, D. Decontamination of egg shells using ultraviolet light treatment. World's Poultry Science Journal, v. 70, n. 2, p. 265-278, 2014.

ÜNSALDI, E.; ÇIFTÇİ, M. K. Formaldehyde and its using areas, risk group, harmful effects and protective precautions against it. Van Veterinary Journal, v. 21, n. 1, p. 71-75, 2010.

VETERÁNY, L.; HLUCHÝ, S.; VETERÁNYOVÁ, A. The influence of ultra-violet radiation on chicken hatching. Journal of Environmental Science and Health, Part A, v. 39, n. 9, p. 23332339, 2004.

WELLS, J. B.; COUFAL, C. D.; PARKER, H. M.; MCDANIEL, C. $D$. Disinfection of eggshells using ultraviolet light and hydrogen peroxide independently and in combination. Poultry Science, v. 89, n. 11, p. 2499-2505, 2010.

YOUSRA, T.; INES, M.; HANENE, C.; ABDENNACEUR, H.; HADDA, O. Effect of biological treatment and ultraviolet (UV)-C radiation disinfection process on wastewater bacterial community as assessed by denaturing gradient gel electrophoresis (DGGE) fingerprints. African Journal of Microbiology Research, v. 7, n. 42, p. 4927-4933, 2013.

ZEWEIL, H. S.; RIZK, R. E.; BEKHET, G. M.; AHMED, M. R. Comparing the effectiveness of egg disinfectants against bacteria and mitotic indices of developing chick embryos. The Journal of Basic \& Applied Zoology, Comparative Anatomy and Embryology. v. 70 , p. 1-15, 2015. 